\title{
Regulatory Application Type
}

National Cancer Institute

\section{Source}

National Cancer Institute. Regulatory Application Type. NCI Thesaurus. Code C70871.

The primary category of an official application to the regulatory agency. It can cause specific types of regulatory requests. The type of application is determined by the nature of the regulated product it supports, the phase of the product development, and other factors. 